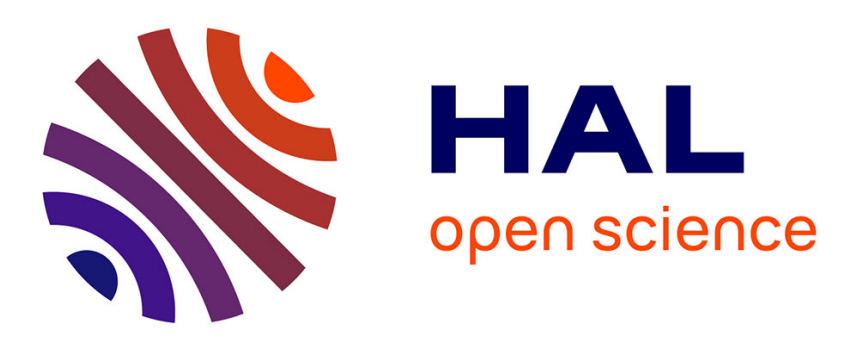

\title{
Assessing urban logistics pooling sustainability via a hierarchic dashboard from a group decision perspective
} Jesus Gonzalez-Feliu, Joëlle Morana

\section{To cite this version:}

Jesus Gonzalez-Feliu, Joëlle Morana. Assessing urban logistics pooling sustainability via a hierarchic dashboard from a group decision perspective. 2014. halshs-01053887

\author{
HAL Id: halshs-01053887 \\ https://shs.hal.science/halshs-01053887 \\ Preprint submitted on 3 Aug 2014
}

HAL is a multi-disciplinary open access archive for the deposit and dissemination of scientific research documents, whether they are published or not. The documents may come from teaching and research institutions in France or abroad, or from public or private research centers.
L'archive ouverte pluridisciplinaire HAL, est destinée au dépôt et à la diffusion de documents scientifiques de niveau recherche, publiés ou non, émanant des établissements d'enseignement et de recherche français ou étrangers, des laboratoires publics ou privés. 


\title{
Assessing urban logistics pooling sustainability via a hierarchic dashboard from a group decision perspective
}

\author{
Jesus Gonzalez-Feliu and Joëlle Morana
}

\begin{abstract}
This paper aims to propose, via an experimental collaborative decision support method, to define a grid of indicators and a reference situation database to measure the sustainable performance of urban logistics pooling systems. To do this, we start by defining the notion of sustainability in the 4As approach, after what we identify the main sustainability indicators from an overview of the literature, and class them into four categories (one for each A of the approach). Then, a group of 20 experts is required and an iterative experimental collaborative decision making method is applied to the group to converge to the concordance of a set of indicators. The method allowed us to define a hierarchic dashboard agreed by all experts with 7 main indicators and 9 secondary indicators. Moreover, the experts signaled the need of defining a unified basis of comparison to estimate initial situations. To do this, we proposed a database of urban routes from the French Surveys on Urban Goods Transport. This method has the advantage of proposing a dashboard agreed by all involved stakeholders. The proposed dashboard is an example and to provide a more unified one the experience has to be iterated using different groups of decision makers. Therefore, this paper shows the patterns to reproduce it, since the method is able to be replicated in any context of group decision in urban logistics. The originality of the paper arises on the use of an experimental group decision method using a group with a majority of practitioners, and to validate it by consensus.
\end{abstract}

Keywords: logistics pooling; sustainable development; group decision support; distribution; consensus.

\section{Introduction}

Sustainable supply chain management is of growing significance to organizations to gain a competitive advantage, but also to industries sensitive to environmental problems or social issues (Seuring and Müller, 2008). Thus the adoption of sustainable supply chain management requires that particular attention be focused on performance management, accounting, auditing and management control. In our view, designing a sustainable dashboard provides a tool for encouraging the application of sustainable supply chain management and allowing stakeholders to discriminate positively in favor of sustainable products and services.

The organizational aspects of urban logistics schemes must be considered in the global sustainable supply chain (Allen and Browne, 2010). Indeed, with increasing urban traffic, some organizations are faced with the problem of ensuring efficient urban freight distribution (Morana, 2014). Additional constraints include relations with public authorities whose motivations for managing product flows are different (i.e. no deliveries to the city-center by modes of transport considered highly pollutant). Urban logistics has been studied as a specific research topic for more than 20 years (Taniguchi et al., 2001; Macharis and Melo, 2011; 
Gonzalez-Feliu et al., 2014) but has been traditionally associated with decision support for public authorities and single decision-makers. However, as pointed out by Boudouin et al. (2014), urban logistics involves several stakeholders of different natures and with different aims and goals, which need to communicate and collaborate.

The work proposed focuses on the performance of urban logistics, and more specifically the performance of a pooled distribution system in urban areas. Indeed, in downstream or distribution logistics, urban logistics is increasingly being organized according to a rationale of pooling, a form of logistics collaboration characterized by, a mutual usage of material or immaterial resources by two or more stakeholders of different supply chains (Gonzalez-Feliu and Morana, 2011). Collaboration is one of the most promising areas of study in supply chain management (Stefansson, 2004). In this context, we observe that collaborative logistics requires sharing both common goals and resources throughout the lifecycle of such collaboration. This lifecycle can be divided into four stages (Simatupang and Sridharam, 2002): (1) the engagement process, (2) inter-dependence management, (3) the implementation of operations, and (4) the evaluation of collaboration. Moreover, collaboration in logistics can take place at both longitudinal and transversal levels. Longitudinal collaboration can be defined as the treatment of management issues in a supply chain common to stakeholders of different echelons, mainly those in direct relation with each other. This common process management is based on complementary knowledge and resource-sharing aimed at the efficient use of synergies to accomplish the different tasks of supply chain planning, deployment, follow-up and control. It is characterized by cooperation and synchronization to ensure better joint planning of a common supply chain. Horizontal collaboration can be defined as "the collaboration between a group of stakeholders of different supply chains acting at the same levels and having analogous needs" (Gonzalez-Feliu et al., 2013). The aim of horizontal collaboration is not a common goal of optimizing the same supply chain but finding synergies between different supply chains at certain stages to obtain gains and savings individually (for example, cost, lead time, service quality or their combinations). In freight transport, the main collaborative issues are related to this second type, since transport ensures the links between the different echelons of supply chains.

Although many works have focused on evaluating the performance of urban logistics (Patier and Browne, 2010; Melo and Costa, 2011), with some dealing more specifically with multi-actor multi-criteria decision support (Macharis et al., 2012), the selection of criteria and indicators generally relies on the researchers' experience, without taking the angle of group decision support into account. Indeed, in most cases the choices concerning evaluation indicators are made on the basis of a single decision-maker, mainly a public authority, that sometimes give the possibility to different stakeholders to define different weights to different criteria. But in urban logistics pooling, the stakeholders most interested in knowing the impacts of such systems are the different transport carriers that have to collaborate with each other. In our context, which derives from that of group decision, decisions are not taken by an 
individual decision-maker but by a group that must reach agreement or consensus (Raifa et al., 2002). Furthermore, there is an increasing demand from the freight transport sector ${ }^{1}$ for standard tools to evaluate such impacts in a unified way.

The aim of this paper is, on the basis of a field experiment, to draw up a sustainable dashboard applicable to logistics pooling. The paper is structured as follows. The next section presents an overview of sustainable development after which the paper proposes an overview of the notion of performance and a synthesis of performance indicators in both supply chain management and urban logistics. The position taken with respect to scientific literature is also defined. Then, the group decision methodology for building a unified set of indicators suitable for urban logistics pooling is presented. Finally, a sustainable dashboard for evaluating urban logistics is proposed in the light of the feedback gained from the group decision-making approach. To complete our proposal, a database of reference situations for this sustainability evaluation is also presented and discussed.

\section{Visions of sustainable development in logistics pooling}

Sustainable development is at base a principle for organizing human life in a context of non-infinite resources (Stivers, 1976). This notion has been well integrated in society since the 1997 Kyoto Protocol of the United Nations Framework Convention on Climate Change ${ }^{2}$ (Depledge, 2000). Although the basic idea of sustainable development is shared by all, its interpretation and applications tend to diverge in the various contexts that can be found. In logistics and goods transport, sustainability is related to taking the main elements into account:

- The economic viability of logistics systems, which can mainly take place to the notion of Supply Chain Management (SCM) (Christopher, 1992) In this context, several indicators have been defined to evaluate the economic suitability of supply chains (Griffis et al., 2007, Gunasekaran and Kobu, 2007).

- Respect for the environment, seen as an opportunity rather than a constraint, in the perspectives of Green SCM (Srivastava, 2007). In this context, we find several concepts like eco-design (Michelini and Razzoli, 2004) and reverse logistics (Rogers and Tibben-Lembke, 1999).

- Last but not least, the social and societal implications of logistics in a Social SCM approach (Morana, 2013). In this context, it seems important to consider both the intraorganizational stakeholders (the employees of the company) and the interorganizational ones (account taken of Stakeholder Theory).

\footnotetext{
${ }^{1}$ Statement pronounced in a set of interviews given in the context of the ANR-MODUM project in France in 2013.

${ }^{2}$ The Kyoto Protocol was adopted in 1997 at the third Conference of the Parties to the UNFCCC (COP 3) in order to stabilize greenhouse gas concentrations in the atmosphere at a level that would prevent dangerous anthropogenic interference with the climatic system. This protocol established that the countries which had signed it were to reduce $\mathrm{CO}_{2}$ emissions by $5 \%$ by 2010 , a target not yet met at global level.
} 
An alternative vision of sustainable development has emerged recently (Macharis, 2014). Instead of taking a classic approach, the author proposes to consider sustainability on the basis of four characteristics, noted as "the four As". This concept, more related to the freight transport component of logistics than industrial or warehousing operations, is organized around the following four elements:

- Awareness is defined as the state or ability to perceive, feel, or be conscious of events. The first step to sustainable development is therefore to be aware of the need to act.

- Act and shift can be intended as the reactivity and capacity to ensure a modal split in order to reduce the nuisance of freight transport. The second step of sustainability can be seen as the will to transform current modes of transport modes $^{3}$ and organization into cleaner and more socially equitable ones.

- Such changes will not however be efficient without the notion of Avoidance, seen as the capacity to avoid increasing the nuisances of logistics and freight transport. Indeed, the third step of sustainability is that of acting to avoid instead of needing to repair later.

- Finally, such avoidance must be combined with Anticipation. Indeed, the fourth step of sustainability is that of forecasting and identifying the possible nuisances of logistics and freight transport in advance in order to avoid them.

\section{Measuring sustainable performance in logistics and freight transport}

According to Morana (2013), performance in a supply chain is not limited to cost efficiency (in other words, profitability for the company or its shareholders). It is important to consider several aspects of performance consistent with both a strategic dimension that federates actions taken to ensure sustainability, and with the aspect of competitive performance which consists in seeking solutions that go beyond a one-dimensional perception of the structure. Moreover, we also need to take into account the perspective of socioeconomic performance, reflecting on internal reconfiguration of organizational and social approaches, but also the inter-organizational and environmental aspects. In urban logistics pooling, performance can be measured according to two viewpoints that do not always converge, despite being complementary: that of supply chain performance and that of urban logistics sustainability.

Generally, the aim of measuring logistics performance is to ensure permanent improvement that leads to the conceptualization and implementation of measurement systems

\footnotetext{
${ }^{3}$ This is a vision "transport" and not "supply chain management". For this reason, the author speaks about transport modes and does not necessarily considers other aspecs of SCM like production or inventorying.
} 
combining diagnostics and decision-aids. If we focus on evaluating SCM with key indicators (KPI: Key Performance Indicators), reference can be made to two key works on the subject, both topical and considered as equally important by both researchers and practitioners. The first is the work of Gunasekaran and Kobu (2007), who proposed a list of 26 indicators to measure logistics performance, completing a previous work (Gunasekaran et al., 2001). The second is that of Griffis et al (2007) who proposed a list of 14 indicators. Although other works have been proposed in the literature, we take into account only the 40 indicators proposed in these two works since they are representative of SCM and most works on the subject refer systematically to at least one of them, so they can be taken as a reference. However, these indicators are defined from an SCM perspective and do not necessarily take into account all the transport component ${ }^{4}$, so they do not fully represent the vision of sustainability given by the 4As. Table 1 gives a classification according to the 4As approach, showing that in SCM only the Awareness and the Anticipation components are well represented. Avoidance and Act and Shift indicators are absent in such works because they do not focus on transport. Indeed, transport modes are not considered, making it impossible to define indicators of modal shift without previously defining transport mode usage. Moreover, environmental aspects are not usually addressed in SCM (Gunasekaran and Kobu, 2007); in this context, the avoidance component is also difficult to fill-in.

\footnotetext{
${ }^{4}$ We can see that only one indicator uses the word "transport" [transport costs]. Moreover, this list does not take environmental indicators and few social/societal indocators.
} 
Table 1 - Main key indicators in supply chain management, consolidated into "awareness" and 'anticipation" indicators

\begin{tabular}{|l|l|}
\hline Awareness indicators (number $\mathbf{= 3 3}$ ) \\
\hline Precision of scheduling; & Percentage of deliveries within lead times; \\
Average time for fulfilling pending orders; & Variability of order cycle time; \\
Average rate of fulfilling order by item; & Process cycle time; \\
Rate of fulfilling whole order; & Product development time; \\
Delivery reliability; & Variety of products/ services; \\
Precision of forecasts; & Return on investment; \\
Inventory costs; & Sales price; \\
Procurement lead time; & Cost of inventory shortage; \\
Production lead time; & Supply chain response time; \\
Ratio of logistics costs over sales; & Transport costs; \\
Logistics costs per unit; & Added value; \\
Obsolescence costs; & Cost of guarantee; \\
Conformity with specifications; & Operating expenses; \\
Conformity with regulations; & Perceived quality; \\
Items picked up per person and per hour; & Perceived value of product; \\
Labor efficiency. & Percentage of pick-up errors. \\
\hline Anticipation indicators (number $=\mathbf{8})$ & \\
\hline Average order cycle time; & Rate of inventory turnover; \\
Order management cycle time; & Weeks procurement; \\
Utilization of capacities; & Sales lost due to inventory shortage; \\
Days delay in fulfilling order. & Flexibility of production. \\
\hline
\end{tabular}

This non exhaustive panorama of the use of logistics performance indicators in companies is, according to us, in line with the evaluation constraints in private organizations but it omits the role of freight transport in logistics. Moreover, sustainability is only partially taken into account, since Act and Shift and Avoidances are not reflected by these indicators.

Whereas global logistics obeys business management principles, urban logistics is generally linked to the actions of several actors, so that "business" perceptions are confronted by those of "local authorities", i.e. the actions and objectives of public authorities. Furthermore, urban logistics projects involve very different sectors, raising questions of feasibility, acceptability and impact of very different natures. Consequently, it is important to take these sectors into account in the quest for performance indicators and choose those that respond to the needs and objectives of each of the parties involved. These indicators are sometimes difficult to measure and access.

Many of the indicators of urban logistics concern goods transport. Indeed, the question of urban logistics inevitably includes that of last kilometer deliveries to recipients. However, the traditional indicators of long distance goods transport (tons transported, tons*kilometer, quantity of energy consumed per ton*kilometer, kilometer travelled empty, etc.) appear relatively irrelevant in the urban environment. The number of shipments, the number of 
packages or the variety of actors concerned, among others, change the way in which this measure is seen.

Different authors have proposed sets of transport sustainability indicators for urban logistics (Taniguchi et al., 2001; Behrends et al., 2008; Patier and Browne, 2010; Melo and Costa, 2011; Vaghi and Percoco, 2011; Morana et al., 2014). By compiling the main indicators of these works we can form the basis of a core set of indicators to evaluate urban logistics. Based on these works we propose the following table:

Table 2 - Selected key indicators for freight transport, classified under the 4Astypology

\begin{tabular}{|c|c|}
\hline \multicolumn{2}{|l|}{ Awareness indicators $($ number $=16)$} \\
\hline $\begin{array}{l}\text { Distance travelled; } \\
\text { Travel time; } \\
\text { Loading/unloading time; } \\
\text { Vehicle fill rate; } \\
\text { Warehouse fill rate; } \\
\text { Ratio of loaded distances over travelled } \\
\text { distances; } \\
\text { Return on investment; } \\
\text { Stopping time. }\end{array}$ & $\begin{array}{l}\text { Service rate; } \\
\text { Turnover generated; } \\
\text { Number of packages/pallets } \\
\text { delivered/picked up; } \\
\text { Number of positions/stops; } \\
\text { Trading area; } \\
\text { Trip regularity; } \\
\text { Distance between stops; } \\
\text { Freight vehicle.kilometers. }\end{array}$ \\
\hline \multicolumn{2}{|l|}{ Act and shift indicators (number $=3$ ) } \\
\hline $\begin{array}{l}\text { Number of vehicles entering the city per } \\
\text { mode; }\end{array}$ & $\begin{array}{l}\text { Vehicle size; } \\
\text { Vehicle capacity. }\end{array}$ \\
\hline \multicolumn{2}{|l|}{ Avoidance $($ number $=10)$} \\
\hline $\begin{array}{l}\text { Energy consumption; } \\
\text { Greenhouse gas emissions; } \\
\text { Pollutant emissions; } \\
\text { Noise level (driving); } \\
\text { Noise level (loading/unloading). }\end{array}$ & $\begin{array}{l}\text { Road occupancy by running vehicles; } \\
\text { Road occupancy by stopped vehicles; } \\
\text { Number of accidents; } \\
\text { Number of fatalities; } \\
\text { Involvement of freight vehicles in accidents. }\end{array}$ \\
\hline \multicolumn{2}{|l|}{ Anticipation (number $=5$ ) } \\
\hline $\begin{array}{l}\text { Customer satisfaction; } \\
\text { Retailers' satisfaction; } \\
\text { Rate of absenteeism from employees. }\end{array}$ & $\begin{array}{l}\text { Ergonomic design/user acceptability; } \\
\text { Number of jobs created, destroyed or } \\
\text { converted. }\end{array}$ \\
\hline
\end{tabular}

The 34 indicators proposed here are classified as a function of the 4As of sustainable development. We observe that most indicators are related to public authority decision-support, while the vision of private companies is underrepresented. In conclusion, supply chain management indicators do not take into account all the elements of sustainable development (being essentially related to the economic performance of the enterprise) and urban logistics indicators mainly reflect public authorities' vision of sustainability. However, it seems important for us to integrate urban logistics in sustainable supply chain management, then to define a grid of indicators capable of measuring sustainability with all its components. Consequently, and to take into account the collaborative nature of logistics pooling, we propose to keep the two sets of indicators (the first focused on supply chain management and 
the second on transport management) presented here as the basis for establishing a sustainability dashboard applied to urban logistics pooling.

\section{The method proposed: reasoning through a collective and collaborative approach}

As shown above, KPI are widely used in literature and practice, but are mainly related to individual decisions. However, and since in logistics pooling decisions are not made unilaterally, the search of consensus is an important stage of the decision-making process in our context. Since logistics pooling is a specific type of horizontal collaboration, we want to focus on group decision-making. In horizontal collaboration, stakeholders have similar functions (in this case, they are transport carriers or transport organizers ${ }^{5}$ ). They are often competitors, but when they converge to find a collaboration strategy, they need to share at least one common interest (for example, the collaboration between Bridgestone and Continental to have a common warehouse in France follows a logic of economic performance, i.e. reducing both inventorying and transport costs) and will react like a group when taking decisions (Raifa et al., 2002). Thus is appears that they require a tool related to group decision and reasoning communities (Evangelou and Karacapilidis, 2007; Yearwood and Stranieri, 2009) and not to individual decisions since the decision processes of reasoning communities are more complex and require particular attention since they combine two types of decision: individual decisions made by each member of the community and a group decision taken by the group as a whole, with or without negotiation. According to Yearwood and Stranieri (2009), the group decision process of a reasoning community involves three main components:

- In the individual reasoning phase each individual decision maker seeks evidence, organizes it and finally forms claims that represent his or her preferred position or beliefs in order to take an individual decision.

- The communication of the reasoning phase describes the transmission of all the aspects of individual reasoning, from the decision itself to the ways each individual arrived at it, and starts a discussion that will support the coalesced reasoning phase.

- Finally, in the coalescence of the reasoning phase a form that represents the reasoning processes acceptable to the entire community is obtained. A coalescing of reasoning does not mean that an agreement on a solution is reached. Rather, coalescing of reasoning reflects the state where each individual's reasoning is understood and accepted as valid by the community even if views diverge to the extent that agreement is impossible.

\footnotetext{
${ }^{5}$ Mainly 3PL and 4PL, sometimes combining own account transport with subcontracting, or Freight forwarders and 5PL not having vehicles and contracting all transport operations to specific transport carriers.
} 
Therefore, when defining a tool for evaluating and assessing urban logistics pooling, it is important to consider the nature of the reasoning community. Therefore, here, we propose a group decision support methodology based on consensus research (Raifa et al., 2002). To do this, it is important to include in the collective reasoning the need to represent sustainability in a suitable way. We thus propose to reason along the lines of the 4As approach developed for logistics and transport, then to follow an interactive method that shows explicitly the three phases of group reasoning decision processes.

We base the proposed methodology on the consensus reaching notion (Yearwood and Stranieri, 2006). However, instead of simulating consensus via quantitative multicriteria methods, like collaborative AHP (Ammarapala and Luxhøj, 2007) or classification methods (Gonzalez-Feliu et al., 2013), we propose an interactive method, such as MAMCA (Macharis et al., 2010). However, contrary to MAMCA, which uses an analytic-based procedure to support decisions, we propose a consensual method (Raifa et al., 2002). To do this, it is important to constitute a commission of experts that will interact and collaborate to choose the most suitable indicators. Thus we aim to use a basic group-decision process structure (Yearwood and Stranieri, 2006). First, the stakeholders will make individual decisions without interactions with the others, if possible. Second, a decision communication phase will be organized to allow the stakeholders to exchange on their choices and the importance of using the different indicators. Third and lastly, a consensus research phase will take place to allow all the stakeholders to take a common decision on which they all agree. In this phase, not finding a common solution but agreeing on the fact it has not been possible to find it can also be an alternative to consider.

To perform the above, we proceeded as follows. A set of experts was constituted that included 4 scientists belonging to different universities, 6 technical and research representatives from non-university public research institutions, 3 operational managers from private companies, 5 project managers from logistics consulting and transport planning software development companies, and 2 representatives from freight transport standardization organizations, thus making a total of 20 experts. In order to guide and support the decision process, we developed the following action plan:

1. Creating a common definition of the scope, goals and targets to reach. The scope here was to measure the sustainability of a logistics pooling system, in a way that the viewpoints and goals of the different stakeholders can be reflected in the resulting evaluation grid. Thus a group decision making method to establish a sustainability dashboard was envisaged. This dashboard had to contain four sets of indicators (one per element of the 4As sustainability approach), and the main targets here were to limit the number of indicators to ensure good readability, as well as to propose at least one per category (to cover all of them). This principle had to been presented to a panel of experts 
that would validate and possibly modify it, then participate in the decision-making process to define an operational sustainability dashboard.

2. Individual decision phase. After validating the scope and targets, the experts were asked to make individual choices to fill a grid of indicators using a list of indicators from which they chose those they considered most pertinent to reach the expected goal, initially without limiting the number of indicators so as to allow adding indicators not on the list. This was done so as not to limit the decision to a choice of a specific number of indicators, and also to allow the decision-makers to identify other suitable indicators to comment on them in the following phases.

3. A meeting had to be organized to discuss the results and choose the most suitable set of indicators, in the sense of the communication of reasoning (Yearwood and Stranieri, 2006). This meeting would allow identifying the common indicators, the important indicators for each stakeholder and feed the communication and collaboration to find a set of indicators and agree on it. In this second part of the meeting, the coalescing of reasoning phase starts.

4. After choosing the indicators, the goal was to present the set of indicators to all the experts in order to reach consensus and validate or modify the group decision. This was to be done to allow the stakeholders to revise and eventually modify the set of indicators and validate the final choice of dashboard. This phase corresponds to the consensus reaching, which can be seen as the logical conclusion of the coalescing of reasoning.

To do this, a first meeting was scheduled to agree on the common scope, goal and targets. Then, an initial list of 74 indicators (both quantitative and qualitative) was proposed to the expert panel 21 days after the first meeting. A second meeting was scheduled one week after presenting the indicators to state on the suitability of the proposed list and to launch the decision communication phase. However, most of the experts agreed during the meeting that the proposed list was too exhaustive; they preferred to decide on the basis of a reduced list of 30 indicators and to have more time to decide on their choices. Thus a reduced list was sent to the experts who had 45 days to examine them after the second meeting. The choices of each expert were discussed and a principle of agreement was sought. The following conclusions were drawn from the meeting:

After that, a third meeting was then scheduled 30 days later to update the indicators and present a final version of the document. A consensus process was defined and after reaching consensual agreement, a final dashboard was presented. This dashboard was accompanied by a technical note reporting the main indicators and its method of estimation. Then, both the final dashboard and the technical note was validated by the same group of experts. This validation, performed by experts external to the indicator definition process, led to a 
discussion on the interest and suitability of each indicator and the global dashboard. Marginal modifications (small changes in secondary indicators and details of form or calculation methods) were introduced but the essence of the proposed dashboard was maintained. We proposed a hierarchical dashboard composed of 7 main indicators and 9 secondary indicators. These indicators were classified according to the 4 As typology of sustainable development. This hierarchy works as follows: for each A (Awareness, Act and shift, Avoidance and Anticipation), one or more primary indicators are defined. The combination of indicators had to be considered as sufficient to state on the sustainability of a logistics pooling scheme for all the stakeholders (either in the internal or the external validation process). However, some stakeholders (mainly logistics managers) showed an interest in having complementary indicators associated with certain main indicators. Consequently, we defined the sets of secondary indicators. They were not essential but could help certain stakeholders to detail several aspects of sustainability, mainly service rates, which were selected as a priority for logistics managers.

\section{Results}

We propose in Table 3 the final hierarchical dashboard obtained after the double validation. To offer an easy-to-read tool usable by the different stakeholders and for different projects, we propose the following classification that presents 7 main indicators (3 for awareness, 1 for Act and shift, 1 for Avoidance and 2 for Anticipation) and 9 secondary indicators (4 for awareness, 3 for Avoidance and 2 for Anticipation). Although no secondary indicators for Act and shift are defined, the main dashboard (composed of 7 main indicators) covers the 4As of sustainability. This is due to the fact that logistics pooling mainly concerns road transport, but we can link the change from pollutant vehicles to clean ones, which is the case of urban logistics pooling systems. 
Table 3 - The key indicators of urban logistics in the 4As sustainability approach

\begin{tabular}{|c|c|c|c|c|}
\hline Category & Nature & Main indicator & Stakeholder & Secondary indicator \\
\hline \multirow[t]{5}{*}{ Awareness } & \multirow[t]{2}{*}{ Economic } & \multirow{2}{*}{$\begin{array}{l}\text { Ratio of loaded km } \\
\text { over travelled } \\
\text { kilometers (weight) }\end{array}$} & \multirow[t]{2}{*}{$\begin{array}{l}\text { Public or } \\
\text { private }\end{array}$} & $\begin{array}{l}\text { Ratio of loaded km over travelled km } \\
\text { (volume) }\end{array}$ \\
\hline & & & & Loading rates (weight and volume) \\
\hline & Economic & Warehouse fill rate & Private & - \\
\hline & \multirow[t]{2}{*}{ Service quality } & \multirow[t]{2}{*}{ Service rate } & \multirow[t]{2}{*}{ Private } & $\begin{array}{l}\text { Percentages of deliveries at goods } \\
\text { destination }\end{array}$ \\
\hline & & & & Percentage of deliveries in time \\
\hline Act and shift & Environmental & $\begin{array}{l}\text { Saving in number of } \\
\text { trucks used }\end{array}$ & $\begin{array}{l}\text { Public or } \\
\text { private }\end{array}$ & - \\
\hline \multirow[t]{3}{*}{ Avoidance } & \multirow[t]{3}{*}{ Environmental } & \multirow{3}{*}{$\begin{array}{l}\text { Greenhouse gas } \\
\text { emissions }\end{array}$} & \multirow{3}{*}{$\begin{array}{l}\text { Public or } \\
\text { private }\end{array}$} & Emissions of $\mathrm{CO}_{2}$ \\
\hline & & & & Emissions of $\mathrm{CH}_{4}, \mathrm{CO}$ \\
\hline & & & & Emissions of NOx \\
\hline \multirow[t]{3}{*}{ Anticipation } & & $\begin{array}{l}\text { Financial indicators } \\
(10 \text {-years IRR) }\end{array}$ & Private & - \\
\hline & \multirow[t]{2}{*}{ Social } & \multirow{2}{*}{$\begin{array}{l}\text { Rate of jobs to be } \\
\text { converted }\end{array}$} & Public & Rate of jobs that could be destroyed \\
\hline & & & & $\begin{array}{l}\text { Rate of potential jobs that could be } \\
\text { created }\end{array}$ \\
\hline
\end{tabular}

We observe that the indicators are in general more specific than those proposed in SCM and transport management literature. Logistics indicators are related to transport loading rates, with and without linking them to traveled distances. However, such indicators must be associated with warehousing performance (in terms of loading rates) and to the general financial balance. No inventorying performance indicators were assigned since the system was aimed at generating collaboration between transport carriers or their directly associated parties (i.e. mainly $2 \mathrm{PL}$ and 3PL), so inventorying was not included in the decisions here. All these indicators as well as those related to service performance can be considered as awareness indicators. Gains in congestion are linked to a reduction in number of trucks, which speaks more to private stakeholders and can be directly associated with Act and shift. Moreover, this indicator was considered useful for both public and private stakeholders. Avoidance indicators underscore the importance of greenhouse gas and pollutant emissions (noise was not selected since transport and logistics practitioners are less sensitive to societal issues than are public authorities). Finally, Anticipation indicators are related to two main questions: the economic viability of the system proposed (via financial indicators like internal rates of return over a 10year time frame - 10 years IRR) or the importance of converting the potential number of employees to be reduced into new and added-value jobs.

These indicators must then be applied to real logistics pooling systems and deal with the Sustainable Supply Chain Management principles of urban logistics (Morana and GonzalezFeliu, 2010) and the 4As vision of sustainability (Macharis, 2014). The aims of the present work were to define the list of indicators, but it is also important to give an indication of how they can be used. The data needed to define the indicators is in general obtained using company data, mainly general information on routes (kilometers and times of each route), and 
carrier financial and commercial data, so they can be calculated at carrier level to produce output indicators that are anonymous and do not violate rules relating to company competitiveness and secrecy. Greenhouse gas and pollution emissions can then be estimated from route details. However, if each company estimates these indicators using a common basis of comparison, part of the possible advantage for the community will be lost, since one of the aims of evaluation is also to establish a comparison between logistics schemes. To ensure this, it is important to have a common reference to compare the different projects and initiatives. Consequently, a reference database was built. This reference can be used to compare projects to a current situation (without taking new actions) and to find which sectors are the most suitable for entry into logistics pooling systems. The aim of the database proposed is to define their main characteristics in terms of size in number of delivery points, type of vehicle in weight capacity, type of freight delivered, mode of management, travelled distances and loading factors, making it possible to define and propose indicators for different types of routes in an initial situation. This database was obtained from the National Survey Database on Urban Goods Transport in France, which contains data on 2111 routes collected in three different cities between 1995 and 1999. Taking into account the quantity and quality of the data collected in the different surveys, 778 of the 2111 routes were selected. A typology of routes taking into account the criteria presented above was established, and the main results are summarized in Table 4. 
Table 4 - Main characteristics of urban routes according to the database proposed

\begin{tabular}{|c|c|c|c|c|c|c|c|c|}
\hline & \multicolumn{4}{|c|}{ Average load of a stop (in $\mathrm{kg}$ ) } & \multicolumn{4}{|c|}{ Average load of a route (in $\mathrm{kg}$ ) } \\
\hline $\begin{array}{c}\text { Route size } \\
\text { category (in } \\
\text { number of } \\
\text { deliveries) }\end{array}$ & $\begin{array}{c}\text { Classical } \\
\text { third } \\
\text { party } \\
\text { transport }\end{array}$ & $\begin{array}{c}\text { Small } \\
\text { parcel } \\
\text { LTL } \\
\text { transport }\end{array}$ & $\begin{array}{l}\text { Consigner } \\
\text { own } \\
\text { account }\end{array}$ & $\begin{array}{c}\text { Consignee } \\
\text { own } \\
\text { account }\end{array}$ & $\begin{array}{l}\text { Classical } \\
\text { third party } \\
\text { transport }\end{array}$ & $\begin{array}{c}\text { Small } \\
\text { parcel } \\
\text { LTL } \\
\text { transport }\end{array}$ & $\begin{array}{l}\text { Consigner } \\
\text { own } \\
\text { account }\end{array}$ & $\begin{array}{c}\text { Consignee } \\
\text { own } \\
\text { account } \\
\end{array}$ \\
\hline $\begin{array}{c}\text { TL routes (1 } \\
\text { delivery) }\end{array}$ & 3937 & - & 3469 & 3940 & 3937 & - & 3469 & 3940 \\
\hline $\begin{array}{c}2 \text { to } 10 \\
\text { deliveries }\end{array}$ & 1336 & 25 & 352 & 1023 & 5804 & 113 & 1794 & 61 \\
\hline $\begin{array}{c}11 \text { to } 20 \\
\text { deliveries }\end{array}$ & 489 & 16 & 103 & 56 & 3898 & 247 & 1440 & 116 \\
\hline $\begin{array}{c}21 \text { to } 30 \\
\text { deliveries }\end{array}$ & 62 & 11 & 30 & - & 1140 & 249 & 1753 & - \\
\hline \multirow[t]{2}{*}{$\begin{array}{c}31 \text { or more } \\
\text { deliveries }\end{array}$} & 52 & 8 & 4 & - & 1181 & 406 & 1143 & - \\
\hline & \multicolumn{4}{|c|}{ Average number of stops } & \multicolumn{4}{|c|}{ Average capacity of vehicles (in $\mathrm{kg}$ ) } \\
\hline $\begin{array}{l}\text { Route size } \\
\text { category (in } \\
\text { number of } \\
\text { deliveries) }\end{array}$ & $\begin{array}{c}\text { Classical } \\
\text { third } \\
\text { party } \\
\text { transport }\end{array}$ & $\begin{array}{c}\text { Small } \\
\text { parcel } \\
\text { LTL } \\
\text { transport }\end{array}$ & $\begin{array}{l}\text { Consigner } \\
\text { own } \\
\text { account }\end{array}$ & $\begin{array}{c}\text { Consignee } \\
\text { own } \\
\text { account }\end{array}$ & $\begin{array}{c}\text { Classical } \\
\text { third party } \\
\text { transport }\end{array}$ & \begin{tabular}{|c} 
Small \\
parcel \\
LTL \\
transport
\end{tabular} & $\begin{array}{c}\text { Consigner } \\
\text { own } \\
\text { account }\end{array}$ & $\begin{array}{c}\text { Consignee } \\
\text { own } \\
\text { account }\end{array}$ \\
\hline $\begin{array}{l}\text { TL routes (1 } \\
\text { delivery) }\end{array}$ & 1 & - & 1 & 1 & 9708 & - & 7646 & 9000 \\
\hline $\begin{array}{c}2 \text { to } 10 \\
\text { deliveries }\end{array}$ & 6 & 8 & 6 & 3 & 8479 & 7669 & 6469 & 5643 \\
\hline $\begin{array}{c}11 \text { to } 20 \\
\text { deliveries }\end{array}$ & 15 & 16 & 16 & 11 & 5824 & 5145 & 6658 & 5872 \\
\hline $\begin{array}{c}21 \text { to } 30 \\
\text { deliveries }\end{array}$ & 25 & 25 & 25 & - & 5721 & 6373 & 4976 & - \\
\hline $\begin{array}{c}31 \text { or more } \\
\text { deliveries }\end{array}$ & 37 & 42 & 36 & - & 5815 & 4832 & 3200 & - \\
\hline
\end{tabular}

We observe that own transport deliveries mobilize less commodities than third party transport. TL transport and small LTL routes have similar deliveries in weight but the vehicles are sometimes different. Concerning third party transport, the average capacity of vehicles travelling FTL and LTL routes comprising up to 10 stops is about $9 t$, i.e. a total weight of about 19t, whereas LTL routes with more than 11 stops are travelled with single trucks of smaller capacity, about 6-7t, i.e. a single truck of $13 \mathrm{t}$. Concerning the average quantity of freight unloaded at each stop (in weight), FLT and small routes (up to 10 stops) involve about $4 \mathrm{t}$ and $1 \mathrm{t}$ per stop, respectively, an average weight that decreases considerably for longer routes (for 11 to 20 stops, the average weight is about $500 \mathrm{~kg}$ and for longer routes, $50-60 \mathrm{~kg}$ ). Regarding small parcel deliveries, no FTL routes were found, and the average number of stops is higher than that of pallet and parcel deliveries (the first category). Weights are low (15 kg on average) with a decreasing trend when the number of stops increases (express deliveries, in general characterized by routes with more than 30 stops, involving average weights of $8 \mathrm{~kg} / \mathrm{stop}$, whereas small parcel non express routes involve weights from 10 to $25 \mathrm{~kg}$ ). 
Own account transport follows different trends, and depends strongly on the activity of the sender. Sender's own account transport follows similar trends to those of third party pallet and parcel deliveries, but with lower weights, except for FTL transport, where weights are similar. However, since the number of routes for this category is higher than that of classical third party transport, the numbers of sender's own account deliveries are higher. Receiver's own account presents two trends: FTL transport (half of the total number of routes in this category) presents higher weights (about 4t/stop) then small pickup routes (up to 20 deliveries) with collected weights of about $61 \mathrm{~kg}$ for routes up to 10 pickup points and higher ones (about $116 \mathrm{~kg}$ in average) for routes from 11 to 20 pickup points.

From this database, and taking into account the statistical distribution of routes in a considered spatial zone, a reference situation can be defined. We report as an example the dashboard obtained in the case of a logistics pooling system resulted of merging 100 routes delivering Paris into 300 other routes going to the same destination. In other words, having 400 routes at the beginning, 100 of them have been cancelled (those routes correspond to the second worst quartile in terms of loading factor, i.e., not the 100 emptiest routes but the 100 following). The deliveries of such routes have then been affected to the closest remaining routes in order to simulate a logistics pooling system. The simulations have been made in the context of the LUMD project (Morana et al., 2014). From those simulations, we can assess the proposed dashboard, which contains only the main indicators ${ }^{6}$ :

Table 5 - An example of use of the proposed dashboard.

\begin{tabular}{|l|l|l|l|}
\hline \multicolumn{1}{|c|}{ Category } & \multicolumn{1}{|c|}{ Nature } & \multicolumn{1}{c|}{ Main indicator } & \multicolumn{1}{c|}{ Values } \\
\hline Awareness & Economic & $\begin{array}{l}\text { Ratio of loaded km over travelled kilometers } \\
\text { (weight), per route }\end{array}$ & $0.51(+21 \%)$ \\
& Economic & Warehouse fill rate, per warehouse (average) & n.a. \\
\cline { 2 - 4 } & Service quality & Service rate & $95 \%(=)$ \\
\hline Act and shift & Environmental & Savings on the number of trucks used & $15 \%$ \\
\hline Avoidance & Environmental & Greenhouse gas emissions & $-22 \%$ \\
\hline Anticipation & Economic & Financial indicators (10-years IRR) & n.a. \\
\cline { 2 - 4 } & Social & Rate of jobs to be converted & $18 \%$ \\
\hline
\end{tabular}

Concerning awareness, we observe that this type of logistics pooling allows to increase the loading rates of each route (an average of $21 \%$ of improvement), but being based on only transport pooling there is no impact on warehouse performance. The simulations have been made in a perspective of maintaining a target service rate of $95 \%$. With $25 \%$ of the routes eliminated (which is traduced to $15 \%$ of trucks not entering the city according to current practices of urban freight transport), it is possible to reduce $\mathrm{CO}_{2}$ by $22 \%$, which is a good indicator that shows the capacity of logistics pooling to avoid environmental nuisances. Moreover, it is important to note that the reduction of the number of trucks (and then the

\footnotetext{
${ }^{6}$ The proposed results are an illustration obtained from simulated data and can be seen as an example of utilization of the dashboard. In this sense, only main indicators are presented, but secondary indicators can be estimated as well.
} 
capacity to act) is traduced by an increase of each route's length, so in consequence an increase of traveled distances, and then polluting emissions. However, using in a good way empty capacities allow to reallocate deliveries to the routes which distance increase is minimal with respect to others, and then contains this distance increase. In consequence, overall travelled distance of remaining routes is lower than the total length of the routes cancelled). Finally, the two anticipation indicators have to be analyzed carefully. Since the pooled system does not imply high investment costs, we can consider that finances are not impacted highly, because of the cost reduction due to the usage of residual capacities instead of specific trucks. However, those costs have not still been estimated in detail, mainly for confidentiality reasons. The number of jobs having to be converted, taking into account the current structure of freight transport professionals, is estimated to $2 \%$, taking into account the current scheduling practices in urban goods transport, the current vehicle uses and the potential of using the cancelled vehicles for other types of transport. In this context, the number of jobs to convert, which is about 8 , can be destined to assistance and added-value tasks and operations related to pooling management, land assistance (mainly for cross-docking and eventual consolidation) or transferred to inventorying and warehousing, when applicable. In any case, the proposed results are a realistic example of logistics pooling that illustrate the usage of the proposed dashboard and show the potential of transferability to the various stakeholders of logistics in urban contexts.

\section{Conclusion}

The evaluation of urban logistics pooling should be seen from the perspective of sustainable development. In this context, we think that the 4As vision of sustainability (Awareness, Act and shift, Avoidance and Anticipation) is a good approach for evaluating the sustainability of urban logistics pooling systems. Likewise, it is advisable to enumerate a limited though sufficient number of indicators for decision making, according to the principle of fast but efficient reading. In addition, the specific characteristics of urban logistics and the two predominant visions (those of private enterprise and public authority, respectively) regarding the problem of goods mobility in urban zones confer strong potential to the evaluation and communication of urban logistics projects.

As seen in the literature analysis, supply chain management indicators do not cover all four components of sustainability in transport, but show several interesting indicators for the private sector. Urban logistics evaluation indicators are more focused on public decisionmakers, and on the case of one decision-maker needing support, and although they propose indicators included in the 4As of sustainability, not all of them seem adapted to measure the sustainability of a system in which a group of private stakeholders must agree on a collaborative logistics system in the context of group decision dynamics. Consequently, using a group decision support methodology, we proposed a grid of indicators to evaluate the 
sustainability of urban logistics pooling systems. Since several stakeholders are involved in such systems and effectively take decisions, it was important to define a dashboard that shows indicators with which the different stakeholders could understand and analyze whether such systems satisfied their aims or not. A group of experts deliberated sequentially on the different indicators to include in the dashboard (first, individual decisions were made; second, a set of meetings took place to ensure communication between the experts, and their agreement on and validation of a final dashboard). In this way, the indicators of the proposed dashboard are organized on two levels. First, a set of 7 indicators that cover all four As of sustainable transport was defined to provide the general state of the sustainable performance of the system with respect to a reference state (this reference state was also estimated using a database of logistics practices in urban areas). Second, a set of 9 indicators was proposed to specify some aspects not included in the first set of indicators but which could be added at the request of certain stakeholders to meet their needs.

This work showed that group decision-making can be applied to evaluate sustainability in urban logistics pooling and provide a set of suitable indicators from an extensive list. However, our aim in this work was not to establish a "standard" grid of indicators as we think that more work must be done to define a unified methodology and a core set of indicators to evaluate the sustainability of urban logistics and ensure the scientific comparison of experiments. To do this, it is important to get both researchers and practitioners (private and public) to collaborate in an open-minded way to find the most suitable set of indicators, taking into account the ways data can be produced and the interpretations that the different stakeholders can make of such indicators. Since the method is directly applicable to practice, it is important to convince users of the power of group decision making and consensus search and encourage the dialog instead of imposition of "solutions" by public bodies, which is still privileged in some urban logistics contexts.

\section{Acknowledgements}

Part of this work was funded in the framework of the LUMD (Logistique Urbaine Mutualisée Durable, Sustainable Urban Pooled Logistics) project by the Inter-Ministerial Unified Funds for Research and Innovation, in its program FUI 2008. The authors would also like to thank the book's editors and two anonymous reviewers for their comments and suggestions to improve this book chapter.

\section{References}

Allen, J., \& Browne, M. (2010). Sustainability strategies for city logistics. In McKinnon, A., Cullinane, S., Browne, M., Whiteing, A. (eds.), Green Logistics: Improving the Environmental Sustainability of Logistics, Kogan Page, London, pp. 282-305.

Ammarapala, V., \& Luxhøj, J.T. (2007). A collaborative multi-criteria decision making technique for risk factor prioritization. Journal of Risk Research, 10 (4), 465-485. 
Behrends, S., Lindholm, M., \& Woxenius, J. (2008). The impact of urban freight transport: A definition of sustainability from an actor's perspective. Transportation Planning and Technology, 31(6), 693-713.

Boudouin, D., Morel, C., \& Gardrat, M. (2014). Supply chains and urban logistics platforms. In Gonzalez-Feliu, J., Semet, F. Routhier, J.L. (eds.), Sustainable Urban Logistics: Concepts, Methods and Information Systems, Springer, Heidelberg, 1-20.

Christopher, M. (1992), Logistics and supply chain management, Pitman Publishing, London.

Depledge, J. (2000). Tracing the Origins of the Kyoto Protocol: an Article-by-article Textual History: Technical Paper. United Nations, UNFCCC Framework Convention on Climate Change.

Evangelou, C.E., \& Karacapilidis, N. (2007). A multidisciplinary approach for supporting knowledge-based decision making in collaborative settings. International Journal on Artificial Intelligence Tools, 16 (06), 1069-1092.

Gonzalez-Feliu, J., \& Morana, J. (2011). Collaborative transportation sharing: from theory to practice via a case study from France. In Yearwood, J.L. and Stranieri, A. (eds.), Technologies for Supporting Reasoning Communities and Collaborative Decision Making: Cooperative Approaches. Information Science Reference, Hershey, pp. 252271.

Gonzalez-Feliu, J., Salanova Grau, J.M., Morana, J. Ma, T.Y. (2013). Design and scenario assessment for collaborative logistics and freight transport systems. International Journal of Transport Economics, 40(2), 207-240.

Gonzalez-Feliu, J., Semet, F., \& Routhier, J.L., eds. (2014). Sustainable urban logistics: Concepts, methods and information systems. Springer, Heidelberg.

Griffis, S.E., Goldsby, T.J., Cooper, M., Closs, D.J. (2007). Aligning logistics performance measures to the information needs of the firm. Journal of Business Logistics, 28(2), 35-56.

Gunasekaran, A., \& Kobu, B. (2007), Performance measures and metrics in logistics and supply chain management: a review of recent literature (1995-2004) for research and applications. International Journal of Production Research, 45(12), 2819-40.

Gunasekaran, A., Patel, C., \& Tirtiroglu, E. (2001). Performance measures and metrics in a supply chain environment, International Journal of Operations \& Production Management, 21(1-2), 71-87.

Macharis, C. (2014). Innovative solutions for sustainable logistics. Presentation at Logistics Day 2014 - Cluster for Logistics, Luxembourg, 28/04/2014, invited speech.

Macharis, C., De Witte, A., Turcksin, L. (2010). The Multi-Actor Multi-Criteria Analysis (MAMCA) application in the Flemish long-term decision making process on mobility and logistics. Transport Policy, 17(5), 303-311.

Macharis, C., Turcksin, L., \& Lebeau, K. (2012). Multi actor multi criteria analysis (MAMCA) as a tool to support sustainable decisions: State of use. Decision Support Systems, 54(1), 610-620.

Macharis, C., \& Melo, S., eds. (2011) City Distribution and Urban Freight Transport: Multiple Perspectives. Edward Elgar, Northampton, 120-149. 
Melo, S., \& Costa, A. (2011). Definition of a set of indicators to evaluate the performance of urban goods distribution initiatives. In Macharis, C., Melo, S. (eds.), City Distribution and Urban Freight Transport: Multiple Perspectives. Edward Elgar, Northampton, pp. 120-149.

Michelini, R.C., \& Razzoli, R.P. (2004). Product-service eco-design: Knowledge-based infrastructures. Journal of Cleaner Production, 12, 415-428.

Morana, J. (2013). Sustainable supply chain management. ISTE-Wiley.

Morana, J. (2014). Sustainable Supply Chain Management in Urban Logistics. In GonzalezFeliu, J., Semet, F., Routhier, J.L. (eds.), Sustainable Urban Logistics: Concepts, Methods and Information Systems. Springer, Heidelberg, pp. 21-35.

Morana, J., \& Gonzalez-Feliu, J. (2010). Sustainable supply chain management in city logistics solutions: lessons learned from the case of Cityporto Padua (Italy). In Proceedings of the $3 \mathrm{rd}$ International Conference on Information Systems, Logistics and Supply Chain, April 14-16, 2010, Casablanca (Moroco).

Morana, J., Gonzalez-Feliu, J., \& Semet, F. (2014). Urban Consolidation and Logistics Pooling. Planning, Management and Scenario Assessment Issues. In Gonzalez-Feliu J., Semet, F., Routhier, J.L. (eds), Sustainable urban logistics: concepts, methods and information systems. Springer, Heidelberg, 187-210.

Patier, D., \& Browne, M. (2010). A methodology for the evaluation of urban logistics innovations. Procedia-Social and Behavioral Sciences, 2(3), 6229-6241.

Raifa H., Richardson J., \& Metcalfe D. (2002). Negotiation analysis - The science and art of collaborative decision making. Harvard University Press, Harvard, Etats Unis.

Rogers, D., \&Tibben-Lembke, R. (1999). Going backwards: reverse logistics trends and practices, Vol. 2. Reverse Logistics Executive Council, Pittsburgh, PA.

Seuring, S., \&Müller M. (2008). From a Literature Review to a Conceptual Framework for Sustainable Supply Chain Management. Journal of Cleaner Production, 16 (15), 16991710.

Srivastava, S. (2007). Green supply-chain management: A state-of-the-art literature review. International Journal of Management Reviews, 9 (1), 53-80.

Stefansson, G. (2004). Collaborative Logistics Management - The Role of Third-Party Service Providers and the Enabling Information Systems Architecture. PhD. Dissertation. Dept. of Logistics and Transportation, School of Technology Management and Economics, Chalmers University of Technology, Sweden.

Stivers, R. (1976), The Sustainable Society: Ethics and Economic Growth, Westminster Press, Philadelphia.

Taniguchi, E., Thompson, R. G., Yamada, T., \& Van Duin, R. (2001), City Logistics. Network modelling and Intelligent Transport Systems. Elsevier, Amsterdam.

Vaghi, C., \& Percoco, M. (2011). City Logistics in Italy: success factors and environmental performance. In Macharis, C., Melo, S. (eds.), City Distribution and Urban Freight Transport: Multiple Perspectives. Edward Elgar, Northampton, 151-175. 
Yearwood, J., \& Stranieri, A. (2006). The generic/actual argument model of practical reasoning, Decision Support Systems, 41, 358-379. Yearwood, J., \& Stranieri, A. (2010). Group structured reasoning for coalescing group decisions. Group Decision and Negotiation, 19(1), 77-105.

Jesus Gonzalez-Feliu is research engineer in data production and analysis the French Centre National de la Recherche Scientifique. Graduated as an engineer from the INSA-Lyon in civil engineering and town planning in 2003, he obtained a MSc in sustainable transport and mobility and then a $\mathrm{PhD}$. in computer and systems engineering at the Politecnico of Turin (Italy). He joined the LET in 2008 as a post-doc before taking on his present position. His main research interests are city logistics demand modelling, multi-stage systems, shopping trip generation and simulation, group decision making, logistics sharing and scenario assessment, among others. He is author or co-author of more than 30 papers in international peer-review journals or books, and more than 20 communications in international conferences. He also coordinated an international scientific book on sustainable urban logistics (Springer) and two special editions of international peer-reviewed scientific journals.

Joëlle Morana, is assistant professor with capacitation to direct $\mathrm{PhD}$. Theses at Université Lumière Lyon 2. After working for 10 years as a cost controller with the multinational STMicroelectronics, she returned to her studies to prepare for an Advanced Studies Degree Strategy option in 1999, followed by her defence of her PhD. thesis in October 2002. Her thesis, on the synergy between Supply Chain Management and Dashboards, was rewarded by the 2002 Prize for a cross-disciplinary thesis in accounting and management. Her main research subjects are sustainable supply chain management, synergy between supply chain management and dashboards, reverse logistics and tracking, among others. She is author or co-author of more than 20 papers in peer-review journals or international books, 3 books (two of them on Sustainable Supply Chain Manangement, published respectively by HermèsLavoissier and Wiley-ISTE) and more than 10 communications in international conferences. 